\title{
Neonatal monocytes exhibit a unique histone modification landscape
}

\author{
Jennifer R. Bermick ${ }^{1 *}$, Nathalie J. Lambrecht ${ }^{1}$, Aaron D. denDekker ${ }^{2}$, Steven L. Kunkel ${ }^{2}$, Nicholas W. Lukacs ${ }^{2}$, \\ Cory M. Hogaboam ${ }^{3 \dagger}$ and Matthew A. Schaller ${ }^{2+}$
}

\begin{abstract}
Background: Neonates have dampened expression of pro-inflammatory cytokines and difficulty clearing pathogens. This makes them uniquely susceptible to infections, but the factors regulating neonatal-specific immune responses are poorly understood. Epigenetics, including histone modifications, can activate or silence gene transcription by modulating chromatin structure and stability without affecting the DNA sequence itself and are potentially modifiable. Histone modifications are known to regulate immune cell differentiation and function in adults but have not been well studied in neonates.

Results: To elucidate the role of histone modifications in neonatal immune function, we performed chromatin immunoprecipitation on mononuclear cells from 45 healthy neonates (gestational ages 23-40 weeks). As gestation approached term, there was increased activating H3K4me3 on the pro-inflammatory $I L 1 B, I L 6, I L 12 B$, and TNF cytokine promoters $(p<0.01)$ with no change in repressive H3K27me3, suggesting that these promoters in preterm neonates are less open and accessible to transcription factors than in term neonates. Chromatin immunoprecipitation with massively parallel DNA sequencing (ChIP-seq) was then performed to establish the H3K4me3, H3K9me3, H3K27me3, H3K4me1, H3K27ac, and H3K36me3 landscapes in neonatal and adult CD14+ monocytes. As development progressed from neonate to adult, monocytes lost the poised enhancer mark H3K4me1 and gained the activating mark H3K4me3, without a change in additional histone modifications. This decreased H3K4me3 abundance at immunologically important neonatal monocyte gene promoters, including CCR2, CD300C, ILF2, IL1B, and TNF was associated with reduced gene expression.

Conclusions: These results provide evidence that neonatal immune cells exist in an epigenetic state that is distinctly different from adults and that this state contributes to neonatal-specific immune responses that leaves them particularly vulnerable to infections.
\end{abstract}

Keywords: Histone modification, Epigenetics, Innate immunity, Development, ChIP-sequencing (ChIP-seq)

\section{Background}

Neonates are uniquely susceptible to infections, with preterm infants (born before 37 weeks of gestation) being the most vulnerable [1]. Up to $25 \%$ of extremely preterm infants develop a culture-positive bacterial infection during their initial hospitalization, which increases their risk of death and long-term neurodevelopmental impairment [2]. Neonatal susceptibility to infection is thought to be due to

\footnotetext{
*Correspondence: jendalto@med.umich.edu

${ }^{\dagger}$ Equal contributors

${ }^{1}$ Department of Pediatrics, Division of Neonatal-Perinatal Medicine, University of Michigan Medical Center, 1540 E. Medical Center Drive, C.S. Mott Children's Hospital Room 8-621, Ann Arbor, MI 48109, USA

Full list of author information is available at the end of the article
}

the need for invasive but life-saving medical interventions, immaturity of the immune system, and disordered regulation of inflammation $[3,4]$.

Protection against infection occurs through the combined efforts of the innate and adaptive immune systems. Monocytes, which mature into macrophages in the tissues, are part of the innate immune system and act as the first line of defense, sensing pathogens and presenting them to cells of the adaptive immune system. Type 1 macrophages express pro-inflammatory cytokines, exhibit strong phagocytic activity, and contribute to the acute inflammatory response, resulting in clearance of pathogens. In contrast, type 2 macrophages express anti-inflammatory cytokines, contribute more to 
the maintenance of chronic inflammation and tissue fibrosis, and are less efficient at clearing pathogens [5]. There is a predominance of type 2 cytokine expression during most normal pregnancies, thought to suppress cellular immunity and protect the fetus from abortive responses [6]. This type 2 cytokine predominance continues in the newborn for several weeks after delivery and in the preterm infant may be prolonged [7]. In neonates, this type 2 skew results in dampened production of the pro-inflammatory cytokines IL-1 $\beta$, IL- 6 , IL-12, and TNF- $\alpha$, impacting their ability to fight infections and clear pathogens [8-12]. Mechanisms controlling developmentally related innate immune system phenotype differences are poorly understood.

Epigenetics studies how genetic and environmental factors interact to alter DNA structure without affecting the underlying genetic code. Epigenetic modifications include DNA methylation, histone modifications, and microRNA expression. These modifications collectively activate or silence gene transcription by influencing chromatin structure and stability or by altering how DNA interacts with transcription factors. The amino acid that is most often modified in histones is lysine, and its position in the histone tail can determine if the added modification allows an open or closed configuration of the gene. The addition of three methyl groups on lysine $(\mathrm{K}) 4$ of histone $(\mathrm{H}) 3$ (i.e., H3K4me3) leads to activation of gene transcription. H3K9me3 and H3K27me3 are both associated with gene silencing as they promote chromatin compaction and make gene promoters inaccessible to transcription factors [13, 14]. H3K4me1 indicates poised enhancers while acetylation of H3K27 (i.e., H3K27ac) marks active enhancers, both of which serve as distal regulators of gene expression [15, 16]. H3K36me3 is associated with either activation or inhibition of gene transcription based on surrounding marks [17].

Histone modifications have been found to underlie normal developmental changes in the immune system, contributing to cell lineage decisions and influencing how cells respond to external stimuli $[15,18]$. There has been increasing interest in developmental-specific epigenetic events that may underlie the unique responses of the neonatal immune system, and some work has evaluated how DNA methylation and microRNA expression impact these responses in term neonates $[19,20]$. Our work is the first to investigate the role of histone modifications in the development and maturation of the neonatal immune system. We demonstrate that in monocytes, a decrease in the poised enhancer mark H3K4me1 parallels an increase in the active promoter mark H3K4me3 as development progresses from neonate to adult. We also show that a lack of H3K4me3 in neonatal monocytes is associated with a reduction in gene expression in vital immunologic pathways. These findings suggest that the unique histone modification landscape in neonatal monocytes may be contributing to the heightened infection risk present in the neonatal period.

\section{Results \\ H3K4me3 increases at mononuclear cell cytokine promoters as development progresses}

To determine if histone modifications contribute to the attenuated pro-inflammatory responses observed in preterm neonates, we performed a chromatin immunoprecipitation assay (ChIP) using anti-H3K4me3 and antiH3K27me3 antibodies to evaluate the promoter regions of the pro-inflammatory cytokine genes $I L 1 B$ (Fig. 1a), IL6 (Fig. 1b), IL12B (Fig. 1c), and TNF (Fig. 1d). The activating histone modification H3K4me3 was significantly increased on the promoters of all four cytokines in term infants, compared to extremely preterm infants (Fig. 1). There was no change in the repressive histone modification H3K27me3 over development on any of the promoters analyzed (Fig. 1). These findings suggest that the IL1B,IL6,IL12B, and TNF promoters of the preterm innate immune system are less accessible to transcription factors than in term neonates, which may contribute to the attenuated pro-inflammatory responses exhibited by preterm infants.

\section{The abundance and location of monocyte H3K4me3 changes throughout development}

To determine the overall profile of H3K4me3 in innate immune cells throughout development, we performed chromatin immunoprecipitation with massively parallel DNA sequencing (ChIP-seq), allowing us to identify all H3K4me3 sites in the monocyte genome. We evaluated the global distribution of H3K4me3 in CD14+ monocytes from four experimental groups: under 30-week preterm infants (U30), over 30-week preterm infants (O30), term infants (Term), and healthy adults (Adult). Figure 2 summarizes the differences in H3K4me3 deposition in monocytes among different developmental stages. A principle component analysis of the H3K4me3 monocyte peak locations and affinity for these locations shows that the preterm monocytes cluster together, the term monocytes cluster together, and the adult monocytes cluster together, but these three groups are distinct from each other both in location and abundance of H3K4me3 (Fig. 2a). A closer look at the total amount of H3K4me3 in the monocyte genome shows that there is an increase in total number of H3K4me3 peaks as development progresses toward term, although the term neonates still have significantly less H3K4me3 than the adults (Fig. 2b). To obtain a broad view of H3K4me3 distribution, we divided the human genome into four distinct categories according to the UCSC Genome 
a

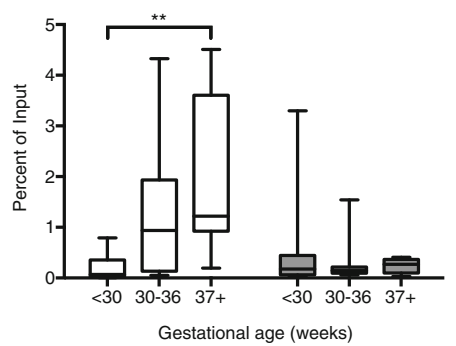

C

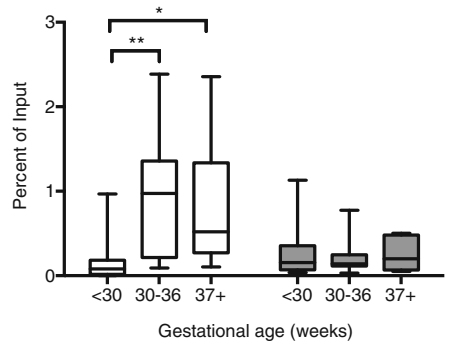

b

IL6 Promoter

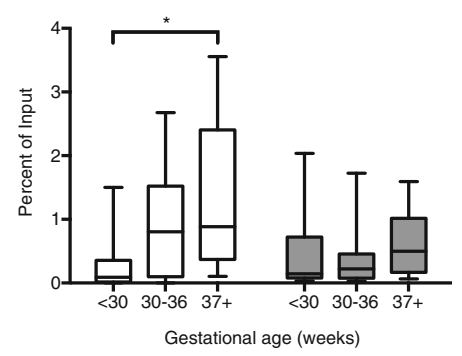

d

TNF Promoter

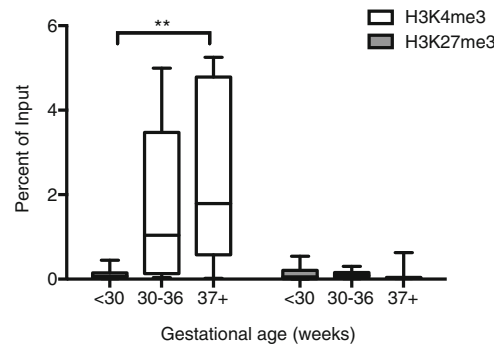

Fig. 1 The activating histone modification H3K4me3 increases on pro-inflammatory cytokine promoters as development progresses over the third trimester. ChIP assays were performed to determine the H3K4me3 and H3K27me3 profiles throughout fetal development of the a IL1B promoter, b $I L 6$ promoter, c $I L 12 B$ promoter, and $\mathbf{d} T N F$ promoter. $<30 n=25,30-36 n=10,37+n=10 .{ }^{*} p<0.05,{ }^{* *} p<0.01$. Box represents 25 th-75th percentile range, and whiskers represent minimum to maximum values

Browser known genes: promoters (1 kb upstream or downstream from transcriptional start sites (TSSs)), exons, introns, and intergenic regions [21, 22]. The majority of H3K4me3 peaks in the preterm monocytes were located in introns and intergenic regions, with less than $5 \%$ of the peaks associated with promoters and exons. There were slightly more H3K4me3 peaks associated with promoter and exon sites in the term monocytes, $\sim 15 \%$, although the majority were still located in noncoding regions of the genome. In contrast, the adult monocytes had the majority of their H3K4me3 peaks located at promoters and exons (70 \%), with only a minority in other regions of the genome (Fig. 2c). Over $75 \%$ of the intergenic H3K4me3 peaks present in the neonatal monocytes were also present in the adult monocytes, suggesting that the intergenic neonatal peaks remained stable as development progressed and that the majority of new H3K4me3 peaks acquired were in promoter and exon locations. The total number of peaks in each location is detailed in Additional file 1: Table S1.

\section{H3K4me3 is associated with distinctly different gene ontology pathways in neonatal and adult monocytes} A large proportion of $\mathrm{H} 3 \mathrm{~K} 4 \mathrm{me} 3$ peaks in the monocytes of all age groups were associated with gene pathways required for cell survival and basic function including metabolism, cell structure, cell signaling, and intracellular transport (Fig. 3a). The major gene ontology pathways that changed over the course of maturation included developmentally related pathways and immunologically important pathways (Fig. 3a). The preterm monocytes had $30-35 \%$ of their H3K4me3 peaks associated with developmentally important pathways, including pathways involved in spinal cord, heart, and renal development. The term monocytes had approximately $10 \%$ of their H3K4me3 peaks associated with developmentally important pathways, while the adult monocytes had no peaks associated with these pathways. Conversely, the U30 monocytes had no H3K4me3 peaks associated with immunologically important pathways, including responses to pathogens, cytokine and chemokine production, and antigen presentation. The O30 monocytes had less than $1 \%$ (4 total) of H3K4me3 peaks associated with immunologically important pathways, while the term monocytes had approximately $6 \%(30$ total) and the adult monocytes had around $8 \%$ (57 total). The immunologically important pathways enriched for $\mathrm{H} 3 \mathrm{~K} 4 \mathrm{me} 3$ are detailed in Additional file 1: Table S2, and the top ranking gene ontology biological pathways enriched for H3K4me3 by age group are shown in Fig. 3b-e. Of note, interferon responsive genes, including IFNB1, CXCL10, and ISG15, did not have differentially bound H3K4me3 between neonatal and adult monocytes.

There were numerous microRNA (miR) promoters with increased H3K4me3 peaks in the adult monocytes. 


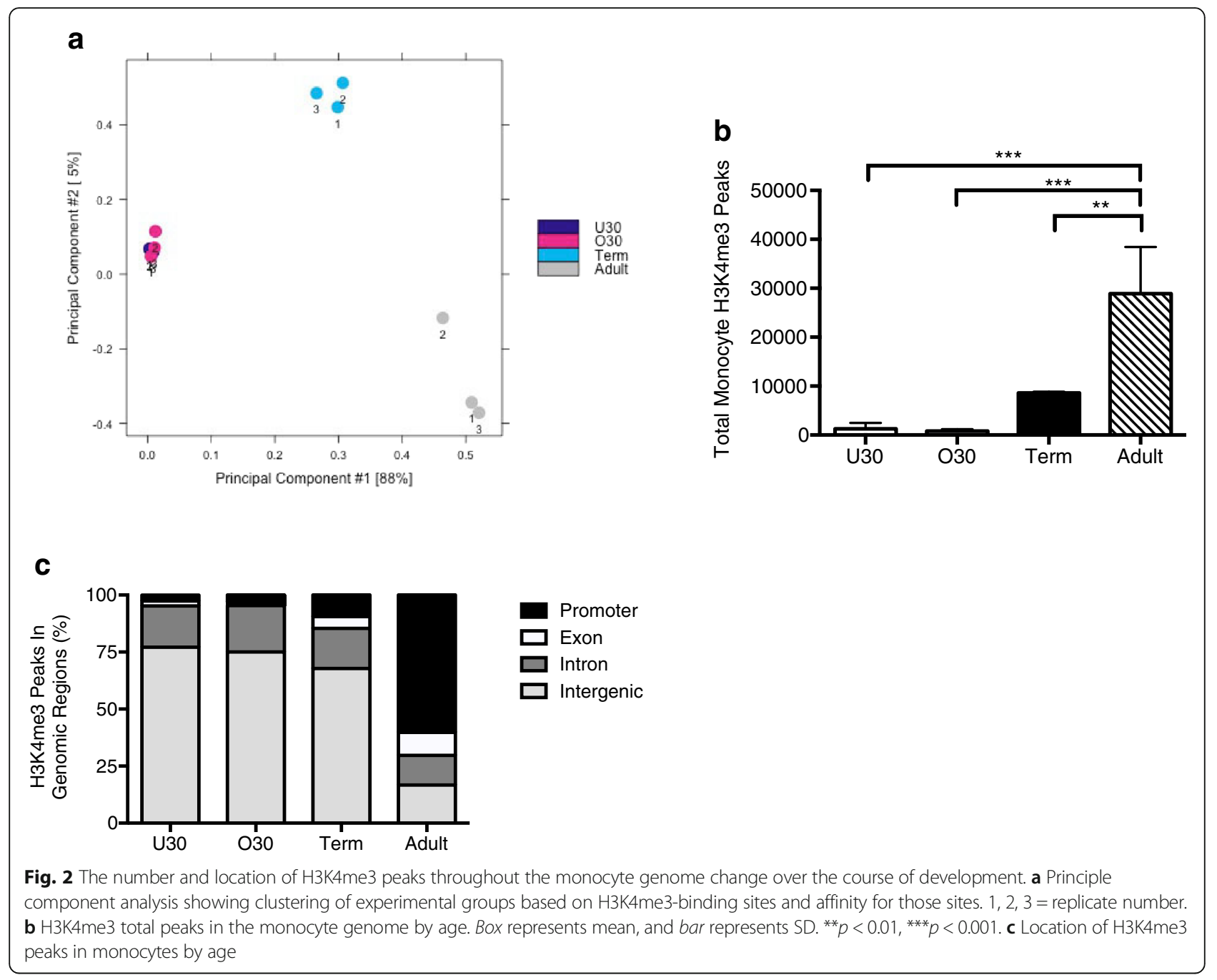

miR-21 is the lone miR identified with known immune function and is involved in the negative regulation of TLR4 signaling [23]. All miRs with differential binding between adult and neonatal monocytes are listed in Additional file 1: Table S3. Immune cell activation requires a metabolic shift from oxidative phosphorylation to glycolysis or lipid metabolism to account for the upregulation of a large number of inflammatory genes, and neonatal immune cells have difficulty undergoing this metabolic shift effectively [24-26]. As a large proportion of H3K4me3 peaks gained over the course of development are in metabolic pathways, we evaluated if differentially bound H3K4me3 peaks between term neonatal and adult monocytes could account for the differences in their ability to undergo this critical metabolic shift. We found multiple genes crucial to glycolysis and lipid metabolism with increased H3K4me3 binding in adult monocytes (Additional file 1: Table S4). The gene ontology pathways associated with $\mathrm{H} 3 \mathrm{~K} 4 \mathrm{me} 3$ peaks present only in the adult monocytes are outlined in Additional file 2: Figure S1.
A decline in monocyte $\mathrm{H} 3 \mathrm{~K} 4 \mathrm{me} 1$ parallels an increase in H3K4me3 during development

To evaluate if histone modifications other than H3K4me3 change significantly over the course of development, we took advantage of ChIP-seq datasets from the Blueprint project (large scale research project generating reference epigenomes for mechanistic studies of health and disease). The Blueprint project has performed ChIP-seq experiments targeting common histone modifications in both adult monocytes and monocytes from term neonatal umbilical cord blood. These experiments include immunoprecipitation of the suppressive marks H3K9me3 and H3K27me3, the enhancer marks H3K4me1 and H3K27ac, and the more versatile mark H3K36me3, which can serve as both an activating and repressive mark. Each Blueprint experiment contains datasets for these histone marks in umbilical cord blood CD14+ monocytes from three healthy term neonates and peripheral blood CD14+ monocytes from three healthy adults. Information obtained from each of these datasets was processed in the 
a

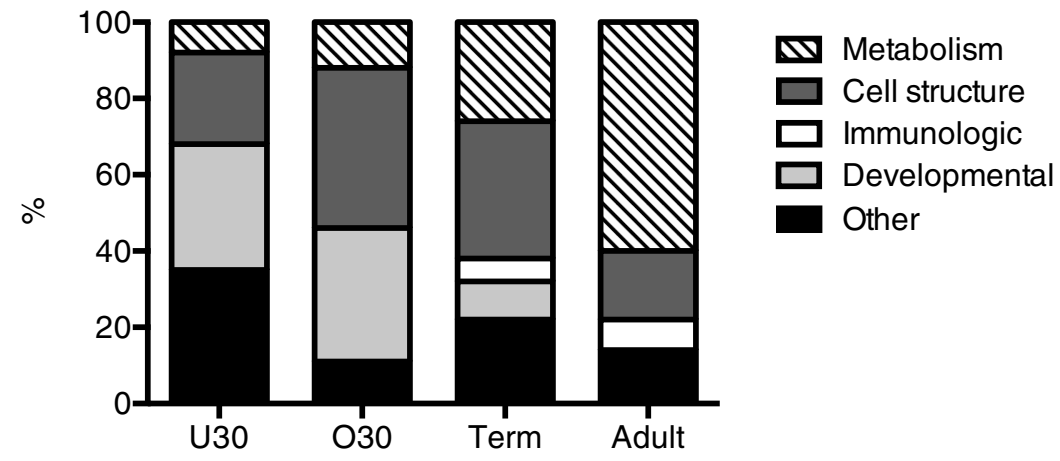

b U30

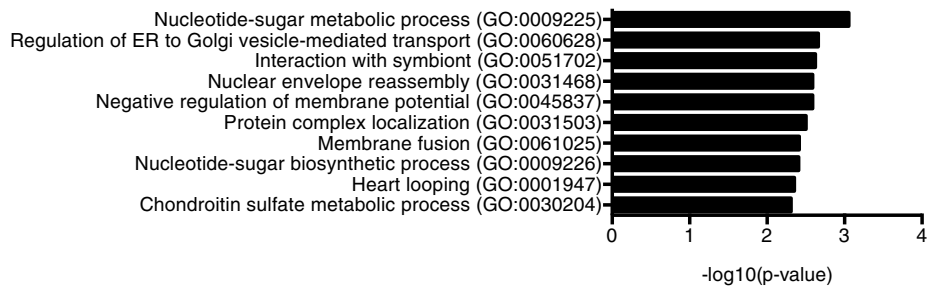

c $\mathbf{0 3 0}$

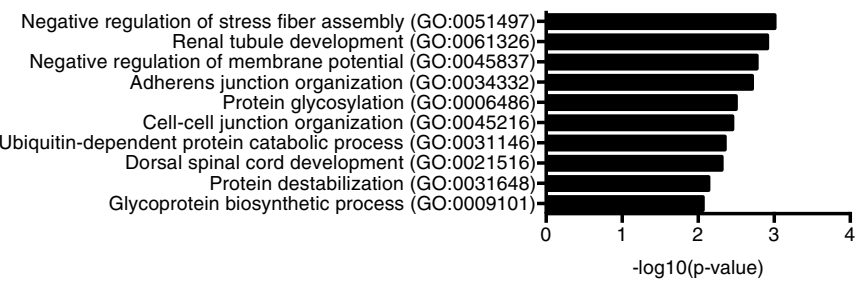

d Term

Negative regulation of stress fiber assembly (GO:0051497) Regulation of plasma membrane organization (GO:1903729)
Regulation of protein localization to plasma membrane (GO:1903076) Clathrin coat assembly (GO:0048268) Protein complex localization (GO:0031503) Protein complex localization (GO:0031503)
Negative regulation of histone modification (GO:0031057)
Cellular response to hypoxia (GO:0071456) Retrograde transport, endosome to Golgi (GO:0042147)

Cyclic nucleotide catabolic process (GO:0009214)

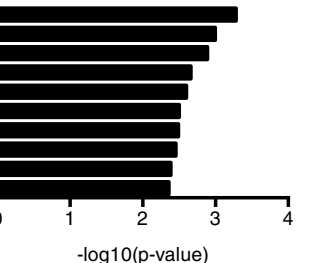

e Adult

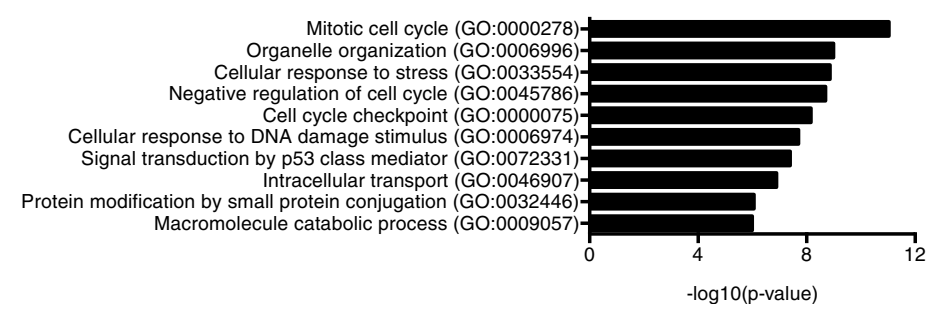

Fig. 3 Gene pathways enriched for H3K4me3 evolve throughout development and into adulthood. a Broad biological gene ontology pathways associated with H3K4me3 monocyte peaks by age. The top non-synonymous biological gene ontology pathways associated with H3K4me3 peaks in $\mathbf{b}$ under 30 week preterm monocytes, c over 30 week preterm monocytes, $\mathbf{d}$ term monocytes, and e adult monocytes 
same fashion as the H3K4me3 monocyte dataset described above. The H3K4me3 dataset used for comparison is from the neonatal and adult samples that we acquired and processed, not from the Blueprint Consortium. Adult monocytes had significantly more H3K4me3 than neonatal monocytes, but less H3K4me1 (Fig. 4a). Both the neonatal and adult monocytes had comparable amounts of H3K9me3, H3K27me3, H3K27ac, and H3K36me3 peaks (Fig. 4a). The broad genomic locations of the H3K9me3, H3K27me3, H3K4me1, H3K27ac, and H3K36me3 marks were not significantly different between the neonatal and adult monocytes (Fig. 4b). A closer analysis of the location of these marks in relation to each other demonstrated that the repressive marks H3K9me3 and H3K27me3 shared similar locations and the activating/enhancing marks H3K4me3, H3K4me1 and H3K27ac shared similar locations, while H3K36me3 had significantly different locations than the other marks (Fig. 4c). The histone modifications with the largest number of differentially bound peaks between neonatal and adult monocytes were H3K4me3 and H3K4me1 (Fig. 4d). There were very few bivalent domains, containing H3K4me3 and H3K27me3 or H3K9me3, in the neonatal and adult monocytes (Additional file 3: Figure S2). These results demonstrate that monocytes lose the enhancer mark H3K4me1 and gain the activating mark H3K4me3 as development progresses from neonate to adult. Other histone modifications stay relatively constant in both number and location.

Given the shift from high H3K4me1/low H3K4me3 in neonatal monocytes to low H3K4me1/high H3K4me3 in adult monocytes, we decided to more closely analyze the location of these marks to determine if some of the

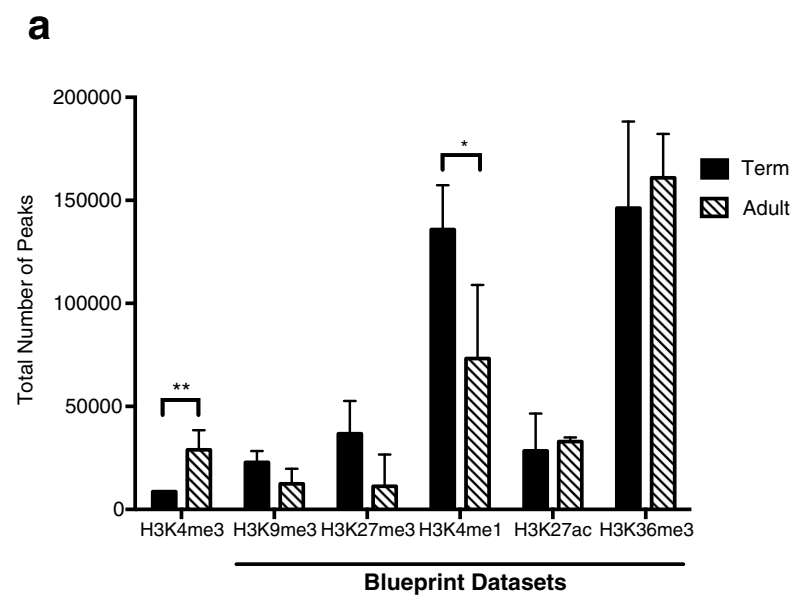

C

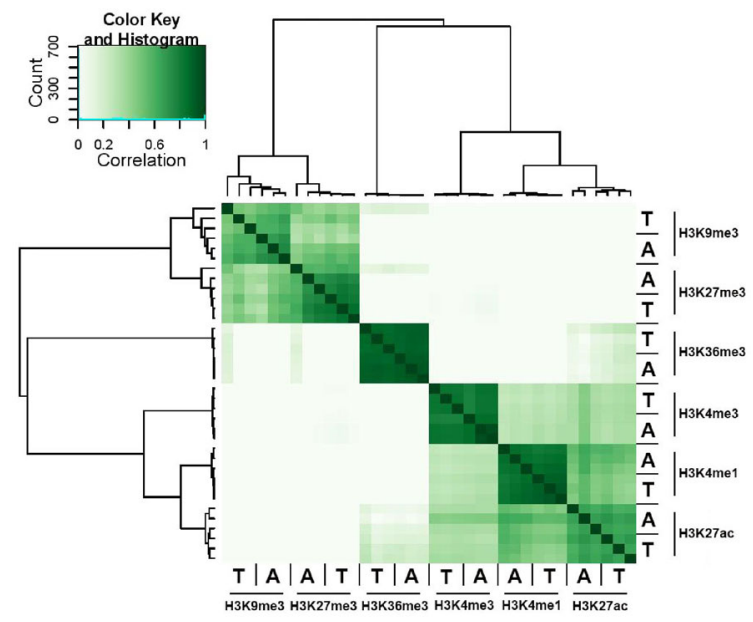

b

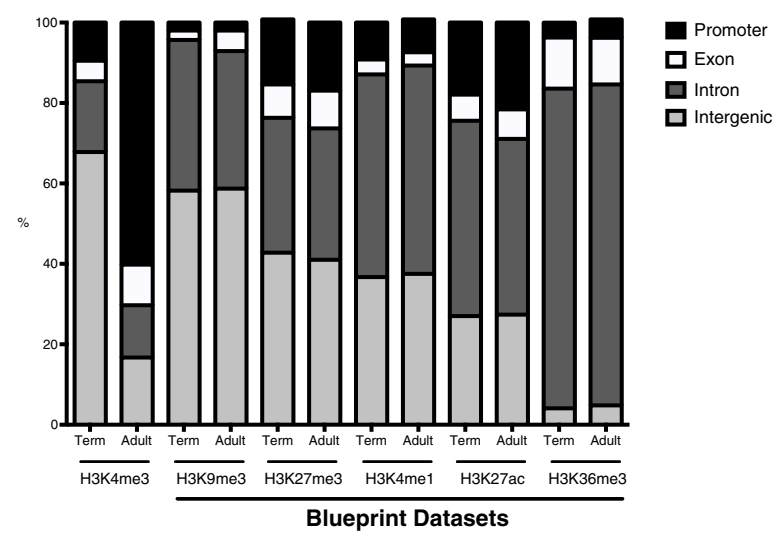

d

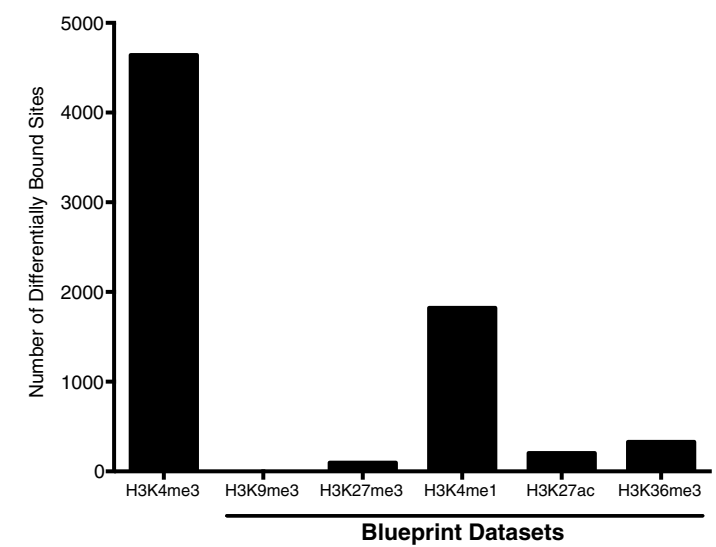

Fig. 4 Monocytes display a decrease in the enhancer mark H3K4me1 with a parallel increase in the activating mark H3K4me3 as development progresses from neonate to adult. a Total monocyte peak numbers of the histone modifications $\mathrm{H} 3 \mathrm{~K} 4 \mathrm{me} 3$ (from our dataset), $\mathrm{H} 3 \mathrm{~K} 9 \mathrm{me} 3, \mathrm{H} 3 \mathrm{~K} 27 \mathrm{me} 3$, H3K4me1, H3K27ac, and H3K36me3 (from the Blueprint Consortium) in term neonatal and adult CD14+ monocytes. ${ }^{*} p<0.05,{ }^{* *} p<0.01$. b Genomic location of histone modification peaks in term neonatal and adult monocytes. c Correlation heatmap comparing histone modification peak occupancy sites. $T=$ term monocytes, $A=$ adult monocytes. $\mathbf{d}$ Number of differentially bound histone modification peaks between neonatal and adult monocytes 
neonatal H3K4me1 marks were being directly converted to H3K4me3 in the adult monocytes or if the additional H3K4me3 marks in the adults were being placed de novo. Sites with increased H3K4me3-binding affinity in adult monocytes were compared to sites with increased H3K4me1-binding affinity in neonatal monocytes, and significant overlap was noted (Fig. 5a). Approximately $12 \%$ of the differentially bound H3K4me3 sites in adult monocytes also contained differentially bound H3K4me1 in neonatal monocytes. The gene ontology pathways associated with these overlapping marks are detailed in Fig. 5b. A closer look at some of these genes revealed that the increased H3K4me1 in the neonatal monocytes shared an identical location with the increased H3K4me3 in the adult monocytes, supporting the hypothesis that a direct conversion between H3K4me1 and H3K4me3 is occurring at some genes during monocyte development (Fig. 5c, d).

\section{The presence and abundance of H3K4me3 in monocytes influences immune function}

Given the association of H3K4me3 with promoter and 5 ' coding regions of actively transcribed genes, we evaluated immunologically important monocyte genes with H3K4me3 peaks surrounding their promoter regions $[27,28]$. The genes evaluated did not have other differentially bound histone modification peaks within $2 \mathrm{~kb}$ of their TSSs. As preterm monocytes had very few H3K4me3 peaks associated with promoter regions, we focused solely on the function of term neonatal and adult monocytes. Neonatal umbilical cord blood CD14+ monocytes and adult peripheral blood CD14+ monocytes a

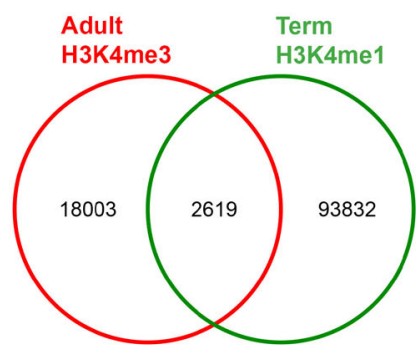

b

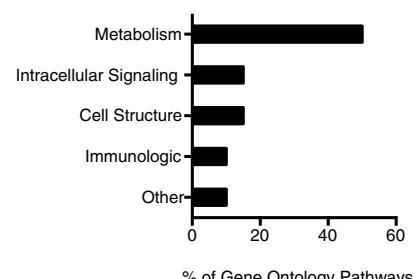

$\%$ of Gene Ontology Pathways

\section{C}

MPEG1

Differentially

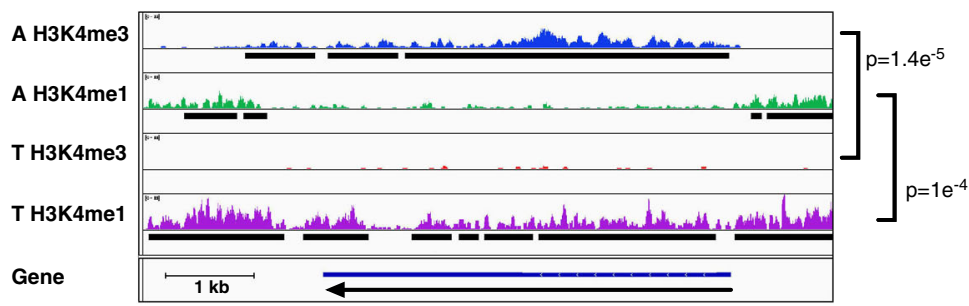

d

$L Y Z$

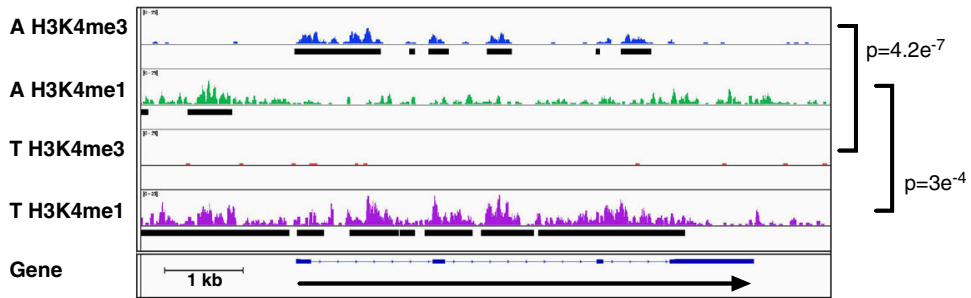

Fig. 5 A subset of H3K4me1 in neonatal monocytes appears to directly convert to H3K4me3 in adult monocytes. a Venn diagram showing that approximately $12 \%$ of H3K4me3 peaks differentially bound between neonatal and adult monocytes have differentially bound H3K4me1 peaks at the same location. b Broad biological gene ontology pathways associated with shared adult H3K4me3 and term neonatal H3K4me1 peaks. c MPEG1 and $\mathbf{d}$ LYZ have significantly increased H3K4me1 across the whole gene in neonatal monocytes without appreciable H3K4me3, which seems to convert to H3K4me3 at identical locations in adult monocytes with a parallel decrease in H3K4me1. A = adult, T= term. H3K4me3 peaks display the read coverage for $\mathrm{H} 3 \mathrm{~K} 4 \mathrm{me} 3$ from one of the representative replicates from each group. Black bars display the H3K4me3 consensus peaks after only peaks present in at least two replicates are combined and analyzed. MPEG1 macrophage expressed 1, LYZ lysozyme 
were cultured in vitro with LPS $100 \mathrm{ng} / \mathrm{mL}$ (TLR4 ligand, simulates gram-negative bacterial infection) or polyI:C $25 \mu \mathrm{g} / \mathrm{mL}$ (TLR3 ligand, simulates viral infection), and messenger RNA (mRNA) expression was measured before culture (unstimulated) or $2 \mathrm{~h}$ after stimulation and receptor surface staining was measured before culture (unstimulated) or $6 \mathrm{~h}$ after stimulation. Neither the neonatal nor adult monocytes demonstrated significant up-regulation of inflammatory gene expression upon polyI:C stimulation, with no difference observed between the neonatal and adult monocyte responses to TLR3 activation. Therefore, the analysis of monocyte function included LPS stimulation only. The evaluated genes were categorized by the amount of bound H3K4me3 shared between adult and neonatal monocytes and whether gene expression was present at baseline or required LPS stimulation to be expressed. The first category of genes had H3K4me3 peaks surrounding promoters in the adult monocytes without any appreciable peaks in the term neonatal monocytes. A subset of these genes had increased gene expression and surface receptor expression at baseline in the adult monocytes (Fig. 6a, $C C R 2$ as example), while another subset had increased gene expression and surface receptor expression in the adult monocytes only after LPS stimulation (Fig. 6b, CD300C as example). The second category of genes had H3K4me3 peaks surrounding promoters in both the adult and term neonatal monocytes but had differential binding with increased binding amount and affinity in the adult monocytes. These genes had increased gene expression in the adult monocytes either at baseline or with LPS stimulation depending on the function of the gene product (Fig. 6c, ILF 2 as example). The third category of genes had comparable H3K4me3 binding near promoters in both adult and term neonatal monocytes with equivalent gene expression and surface receptor expression both at baseline and upon LPS stimulation (Fig. 6d, CXCR4 as example). Representative flow cytometry plots for these surface receptors are shown in Additional file 4: Figure S3. The top 50 genes with differentially bound H3K4me3 near their promoter sites can be found in Additional file 1: Table S5. Consistent with our conventional ChIP data, there was increased H3K4me3 binding at the promoter sites of $I L 1 B$ and TNF with increased mRNA gene expression and secreted protein levels upon LPS stimulation (Additional file 5: Figure S4). These results suggest that both the presence and abundance of H3K4me3 at gene promoters are critical to promoting active gene expression, rather than peak presence alone. Figure 7 summarizes the main findings of this study.

\section{Discussion}

Around the time of birth, the immune system has to transition from a sterile intrauterine environment to an environment full of foreign antigens and microbes. During this transition, the neonatal immune system must avoid excessive pro-inflammatory responses so that rapid colonization of the skin and gastrointestinal tract with beneficial microbial organisms can occur $[29,30]$. Disruption in normal neonatal microbial colonization can have long-lasting deleterious effects and is thought to contribute to the development of allergic diseases, including asthma [31, 32]. The fetal and neonatal immune system polarization toward immunomodulatory type 2 cytokine responses rather than more adult-like pro-inflammatory type 1 cytokine responses not only aids in this transition but also leaves neonates highly susceptible to infections [3, 7]. The factors controlling the developmental progression of immature neonatal immune responses to mature adult immune responses are poorly understood, leaving a large deficit in our ability to prevent, diagnose, and effectively treat neonatal infections. The present study strongly suggests that alterations in H3K4 methylation contribute to neonatal innate immune deficits, especially noteworthy in preterm infants.

Our study is the first to evaluate the contribution of histone modifications to the neonatal immune response and demonstrates that monocytes have a developmentally regulated loss of the poised enhancer mark H3K4me1 with a concurrent gain of the activating mark H3K4me3. Other histone modifications including H3K9me3, H3K27me3, H3K27ac, and H3K36me3 stay relatively constant in both number and location throughout development and are unlikely to make a significant contribution to developmental specific changes in monocyte function. The poised enhancer mark H3K4me1 and the active promoter mark H3K4me3 do not co-localize, with genes either demonstrating high $\mathrm{H} 3 \mathrm{~K} 4 \mathrm{me} 1$ and low H3K4me3 or the converse. This may reflect the conversion of H3K4me1 to H3K4me3 through the intermediate $\mathrm{H} 3 \mathrm{~K} 4 \mathrm{me} 2$ rather than a complete loss or gain of histone methylation at these sites [33, 34]. In agreement with this, we have identified a subset of genes in which H3K4me1 appears to be directly converted to H3K4me3 as development progresses with genes moving from a "poised" to an active configuration. This subset of genes only comprises a small amount (12\%) of the H3K4me3 gained in monocytes as development progresses, suggesting that the majority (88 \%) of H3K4me3 is deposited de novo.

H3K4me3 is typically located at promoter regions of actively transcribed genes [22, 27], so it is interesting that the majority of $\mathrm{H} 3 \mathrm{~K} 4 \mathrm{me} 3$ in neonatal monocytes is in noncoding regions of the genome, including introns and intergenic regions. It is unclear what role H3K4me3 is playing in these locations, but it may be serving a distal regulatory role that has not previously been described. Most of the neonatal H3K4me3 intergenic peaks are also present in the adult monocytes, so it appears that the majority of the new H3K4me3 peaks 


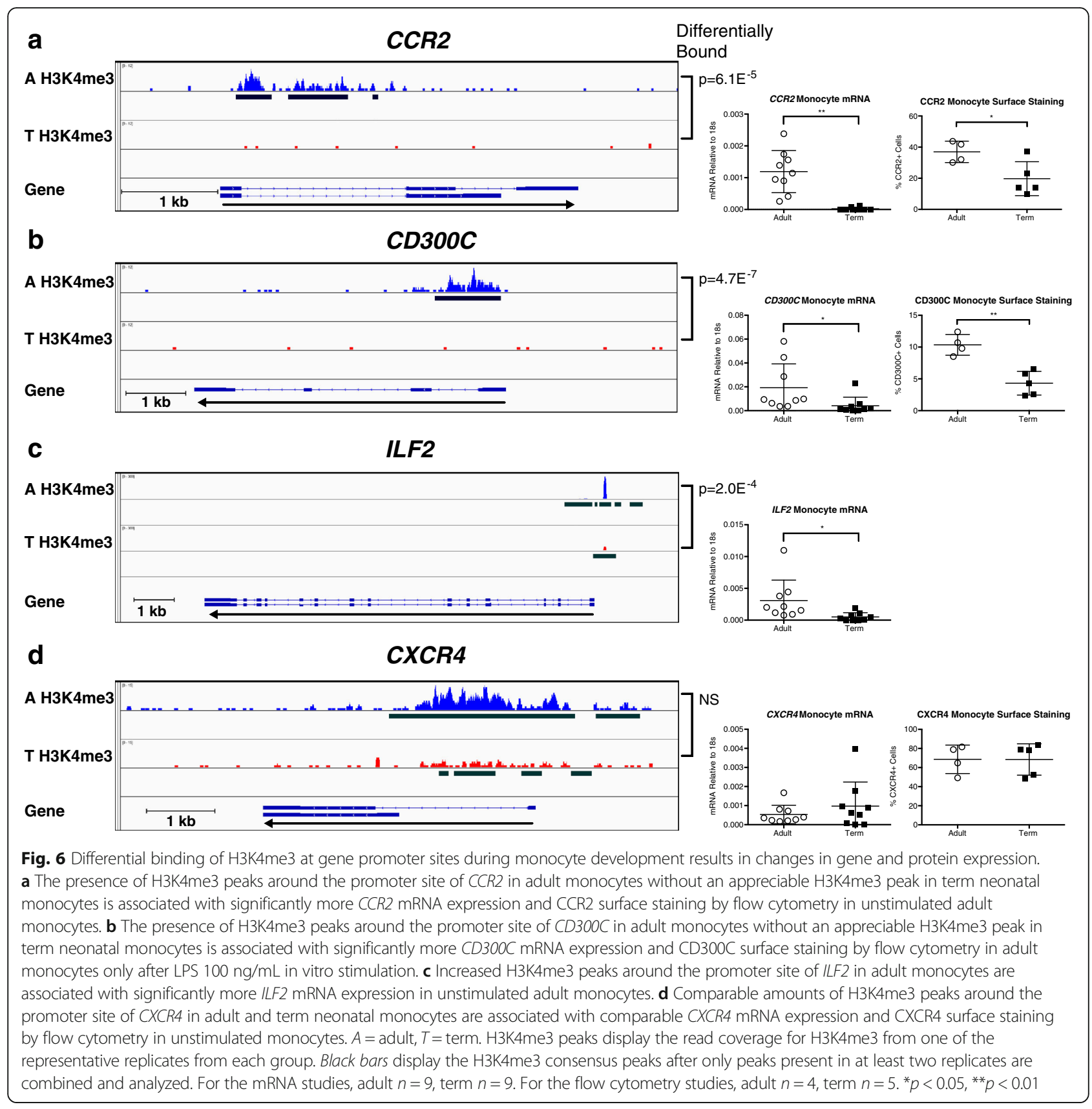

gained throughout development are being deposited in promoter and exon locations. Distinct differences also exist in gene ontology pathways associated with H3K4me3 in neonatal and adult monocytes. Neonatal monocytes have numerous H3K4me3 peaks associated with developmentally related pathways, but these peaks are not present in adult monocytes. The neonatal monocytes also have significantly less metabolic pathways associated with H3K4me3, which is important because a metabolic shift from oxidative phosphorylation to either glycolysis or lipid metabolism is required to accommodate the induction of a large number of genes upon immune cell activation [24, 25]. Recent evidence suggests that neonatal immune cells lack the ability to perform this metabolic shift [26]. We identified multiple genes crucial to glycolysis and lipid metabolism containing H3K4me3 peaks in adult monocytes with decreased or absent H3K4me3 peaks in the neonatal monocytes. In light of this, we believe that H3K4me3 may be an important factor regulating the ability of monocytes to undergo this critical metabolic shift, and a lack of this mark in metabolic pathways in neonatal monocytes may contribute to their dampened inflammatory response. In addition, adult monocytes have significantly more H3K4me3 peaks associated with immunologically important pathways than 


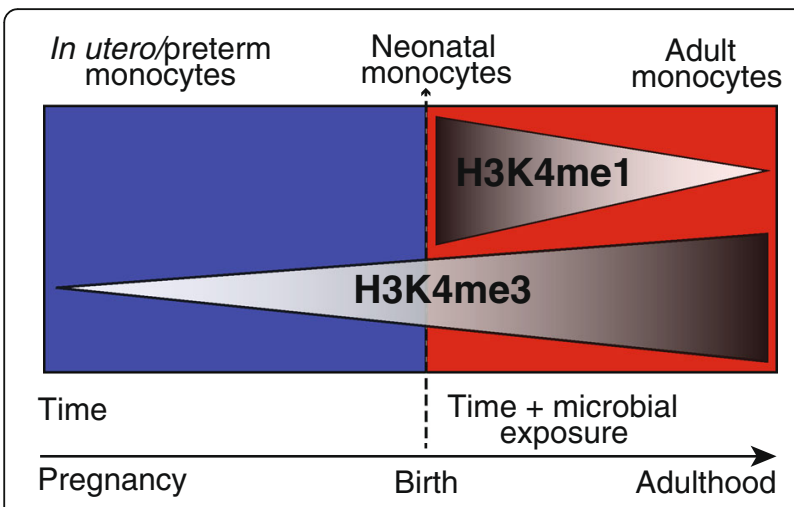

Fig. 7 Proposed scheme of the evolution of the monocyte histone modification landscape over the course of development from preterm neonate to adult

neonatal monocytes, and the expression of some genes vital to the monocyte inflammatory response to pathogens are decreased in neonates due to either a complete absence of or decreased abundance of H3K4me3 at their promoters. There are also numerous miR promoters with increased H3K4me3 in adult monocytes, suggesting that the ability to perform nuanced regulation of complex pathways in monocytes is not fully developed until adulthood. The increased H3K4me3 gained by monocytes during development appears to "mature" the immune system, resulting in more robust and appropriate inflammatory responses and optimal clearance of pathogens. Taken together, these results suggest that neonatal immune cells exist in an epigenetic state that is distinctly different from adult immune cells and that this epigenetic state is a major contributor to neonatal specific immune responses.

The increase in H3K4me3 deposition that occurs between extremely preterm and term infants appears to be triggered solely by stage of development, as these monocytes have yet to be exposed to the ex-utero environment. This is consistent with what occurs during gamete formation and early embryo development, when conserved posttranslational histone modification additions and removals allow reprogramming of the epigenetic landscape during a critical developmental window [35]. However, the increase in total H3K4me3 deposition between term neonatal to adult monocyte likely results from a combination of developmental-specific and environmental exposure-related triggers. Stimulation of immune cells by pathogens or cytokines can prompt the deposition or removal of H3K4me3 at functionally important genes and is critical for the establishment and maintenance of macrophage and $\mathrm{T}$ cell phenotypes [36-39]. Other environmental exposures can also alter histone modification patterns, including highfat diet, diabetes-associated hyperglycemia, and environmental pollutants and toxins [40-43]. These exposureinduced epigenetic alterations have also been shown to occur at the level of bone marrow progenitor cells and can be inherited by daughter cells, resulting in permanent and heritable changes in histone modification patterns in hematopoietic cells [41]. We postulate that the increased H3K4me3 deposition seen in monocytes over the course of postnatal development is prompted by exposure to the exutero environment. We believe these environmental stimuli prompt the appropriate methyltransferase(s) to deposit H3K4me3 at and around gene promoter sites to remodel the epigenetic landscape of the monocytes to a more mature and functional state.

There are some limitations to this study. We attempted to control for expected variability in primary human monocytes by using pooled neonatal samples and three replicates in our ChIP-seq experiments, but there may have been some sex-specific or genetic variability in $\mathrm{H} 3 \mathrm{~K} 4 \mathrm{me} 3$ patterns that were masked by this approach. Additionally, while we evaluated a broad number of histone modifications throughout monocyte development, there are likely other factors that influence developmental-specific changes in monocyte function, including other histone modifications (H3K79me2, H3K9ac, H4K20me1), DNA methylation, miR expression, and non-epigenetic factors that were not included in our study.

\section{Conclusions}

Our study reveals an increase in monocyte H3K4me3 deposition at promoter sites of immunologically and metabolically important genes as development progresses from neonate to adult, which correlates with the ability to mount a more robust inflammatory response. These results show that neonatal monocytes have a unique histone modification landscape that contributes to their attenuated response to pathogens and contributes to the neonate's vulnerability to infection. Further studies are needed to determine the factors regulating this developmental change in monocyte H3K4me3 amount and location and whether these factors can be targeted to improve neonatal outcomes before, during, and after infection.

\section{Methods}

\section{Participants}

The research protocol was approved by the local Institutional Review Board, and written informed consent was obtained from adult participants and parents of all neonatal participants. We prospectively enrolled term (gestational age $>37$ weeks), late preterm (gestational age 30-36 weeks), and extremely preterm (gestational age $<30$ weeks) infants born at the University of Michigan Medical Center, between May 2012 and August 2015. Exclusion criteria included the presence of histologic chorioamnionitis. We enrolled a total of 16 adults and 34 extremely preterm, 19 late preterm, and 33 term infants. 


\section{Blood}

Peripheral blood was collected from participating healthy adults. Umbilical cord blood was collected from participating infants immediately after the delivery of the placenta. The blood was sent to the University of Michigan blood bank and was stored at $4{ }^{\circ} \mathrm{C}$. The umbilical cord blood samples were retrieved from the blood bank and were processed anywhere from day of life 1 through day of life 33, based on when parental informed consent was obtained. The day of sample collection and processing had no effect on the histone methylation of any of the promoters studied. Cord blood samples used to measure mRNA expression were collected no later than day of life 5. Diluted blood (1:2 with sterile $0.9 \%$ saline) was used to harvest umbilical cord mononuclear cells by Ficoll-Isopaque density gradient centrifugation. Mononuclear cells were used for chromatin immunoprecipitation. Mononuclear cells were also subjected to CD14+ magnetic cell isolation according to the manufacturer's instructions (Miltenyi Biotec). On average, the purity of the monocytes was greater than $90 \%$ by CD14 flow cytometry. Isolated CD14+ cells were aliquoted into cryovials in recovery cell culture freezing media (Life Technologies) and were stored at $-80{ }^{\circ} \mathrm{C}$ prior to use.

\section{Chromatin immunoprecipitation (ChIP)}

The total cells used for ChIP ranged from $8.0 \times 10^{5}-4.1 \times$ $10^{6}$ per sample. Cells were fixed for $10 \mathrm{~min}$ at $37{ }^{\circ} \mathrm{C}$ in $18.5 \%$ paraformaldehyde. Glycine $\times 10$ was added to quench extra paraformaldehyde. Cells were washed on ice with ice-cold PBS, were lysed in SDS lysis buffer (1 \% SDS, $10 \mathrm{mM}$ EDTA, $50 \mathrm{mM}$ Tris- $\mathrm{HCl}$ ), and underwent syringe passage three times with a 27 -gauge needle. The DNA was sheared by ultrasonication for $3 \times 10 \mathrm{~s}$ pulses at $50 \%$ amplitude (Branson Digital Sonifier 450). The lysates were cleared by centrifugation and were diluted in ChIP dilution buffer $(0.01 \%$ SDS, $1.1 \%$ Triton X-100, 2 mM EDTA, $20 \mathrm{mM}$ Tris- $\mathrm{HCl}, 150 \mathrm{mM} \mathrm{NaCl}$ ). A sample of "input DNA" was collected, totaling $5 \%$ of the total chromatin, and was stored at $4{ }^{\circ} \mathrm{C}$. Protein-DNA complexes were immunoprecipitated with $4 \mu \mathrm{g}$ of the following antibodies overnight at $4{ }^{\circ} \mathrm{C}$ with rotation: IgG (Millipore, PP64B), H3K4me3 (Abcam, ab8580), and H3K27me3 (Active Motif, 39155). Antibody-protein-DNA complexes were captured using salmon sperm DNA/protein A-agarose beads for $1 \mathrm{~h}$ at $4{ }^{\circ} \mathrm{C}$ with rotation. The bead complexes were washed with low-salt immune complex buffer $(0.1 \%$ SDS, $1 \%$ Triton X-100, 2 mM EDTA, $20 \mathrm{mM}$ Tris-HCl, $150 \mathrm{mM}$ $\mathrm{NaCl})$, high-salt immune complex buffer (0.1\% SDS, $1 \%$ Triton X-100, $2 \mathrm{mM}$ EDTA, $20 \mathrm{mM}$ Tris- $\mathrm{HCl}, 500 \mathrm{mM}$ $\mathrm{NaCl}), \mathrm{LiCl}$ immune complex buffer $(0.25 \mathrm{M} \mathrm{LiCl}, 1 \%$ NP40, 1 \% deoxycholate, 1 mM EDTA, $10 \mathrm{mM}$ Tris- $\mathrm{HCl}$ ), and TE buffer (10 mM Tris-HCl, $1 \mathrm{mM}$ EDTA). The protein-DNA complexes and the "input DNA" were then eluted using a $1 \% \mathrm{SDS}, 0.1 \mathrm{M} \mathrm{NaHCO}_{3}$ buffer and were disrupted by heating at $65{ }^{\circ} \mathrm{C}$ for 5-24 h. DNA was extracted using phenol/chloroform and ethanol precipitation. Real-time PCR was conducted with the ABI Prism 7700 Sequence Detection System using the SYBR Green PCR reagent (Applied Biosystems) following the manufacturer's instructions. Dissociation curve analysis was performed for all primers to ensure a single product with the expected melting curve characteristics. PCR was conducted using promoter-specific ChIP primers (Additional file 1: Table S6). Percent of input was calculated as follows: $\%($ ChIP $/$ Total input $)=2^{\wedge}\left[\left(\mathrm{Ct}_{\text {input }}-\log \{20,2\}\right)-\mathrm{Ct}_{\mathrm{ChIP}}\right] \times$ $3 \times 100 \%$.

\section{Cell culture}

Cryovials of CD14+ cells were thawed, and cells were washed twice in sterile RPMI. Cells were then plated in 96-well polystyrene culture plates at $5 \times 10^{4}$ cells/well in $100 \mu \mathrm{l}$ of RPMI medium containing $400 \mathrm{mM} / \mathrm{L} \mathrm{L-glutam}$ ine, $10 \%$ adult human serum, $1 \%$ penicillin/streptamycin, $1 \%$ sodium pyruvate, and $1 \%$ nonessential amino acids. The cells were stimulated with $100 \mathrm{ng} / \mathrm{mL}$ lipopolysaccharide (Sigma, purified from E. coli 055:B5) or $25 \mu \mathrm{g} / \mathrm{mL}$ polyI:C (Invivogen) and were incubated at $37{ }^{\circ} \mathrm{C}$ and $5 \%$ $\mathrm{CO}_{2}$. Cells were collected for mRNA processing 0 and $2 \mathrm{~h}$ after stimulation, and supernatant was collected for protein analysis $24 \mathrm{~h}$ after stimulation. Cells were collected for flow cytometry 0 and $6 \mathrm{~h}$ after stimulation.

\section{mRNA and protein measurement}

At the time of cell collection, the cells were separated from the supernatant by centrifugation at 5000 RPM for 5 min at $4{ }^{\circ} \mathrm{C}$. Cellular mRNA was then extracted and purified using an RNeasy Micro Kit (Qiagen) according to the manufacturer's instructions. Complementary DNA was synthesized using murine leukemia virus reverse transcriptase (Applied Biosystems) and incubated at $37{ }^{\circ} \mathrm{C}$ for $90 \mathrm{~min}$, followed by $95{ }^{\circ} \mathrm{C}$ for $5 \mathrm{~min}$ to stop the reaction. Real-time quantitative PCR was multiplexed using Taqman primers with a FAM-conjugated probe and $18 \mathrm{~s}$ with a VIC-conjugated probe (Applied Biosystems) to measure transcription of CCR2, CD300C, ILF2, CXCR4, IL1B, and TNF. Resulting mRNA levels were normalized to the housekeeping gene $18 \mathrm{~s}$ and compared using the $\triangle \mathrm{CT}$ method. All reactions were run on an ABI Prism 7700 Sequence Detection System using Universal PCR reagent (Applied Biosystems). The protein levels of the cytokines IL-1 $\beta$ and TNF were measured from cell culture supernatants by Bioplex assay (Bio-Rad).

\section{Flow cytometry}

CD14+ monocytes were resuspended in PBS with $1 \%$ FCS and $0.002 \mathrm{M}$ EDTA, and Fc receptors were blocked 
with purified human IgG. Surface markers were identified using antibodies (clones) against the following antigens, all from BioLegend: CD14 (M5E2), CCR2 (K036C2), CD300C (TX45), and CXCR4 (12G5) each at a 1:100 dilution. Cells were labeled according to the manufacturer's instructions. Flow cytometry was performed on a NovoCyte machine with 405, 488, and $640 \mathrm{~nm}$ lasers.

\section{High throughput sequencing}

Purified umbilical cord blood CD14+ monocytes (including both CD16- and CD16+ subsets) of extremely preterm infants ( $<30$ weeks gestation), late preterm infants $(30-$ 36 weeks gestation), term infants (37+ weeks gestation), and healthy adults were used for ChIP-seq. Each age group contained three biological replicates. To obtain approximately $1 \times 10^{6}$ cells per immunoprecipitation, each neonatal sample replicate contained three pooled samples (Additional file 1: Table S7). ChIP was performed as described above, with modification of the following ultrasonication settings: $40 \%$ amplitude, $0.7 \mathrm{~s}$ 'on', and $1.3 \mathrm{~s}$ 'off' for $240 \mathrm{~s}$ on wet ice. The immunoprecipitation was performed with $4 \mu \mathrm{g}$ of the H3K4me3 antibody (Abcam, ab8580). DNA from each ChIP experimental group was treated with $30 \mu \mathrm{g}$ RNase-A (Qiagen) and was incubated at $37^{\circ} \mathrm{C}$ with intermittent shaking for $1 \mathrm{~h}$. The samples were purified using a MinElute PCR purification kit (Qiagen) following the manufacturer's instructions. End repair of the sonicated DNA was performed by incubating the samples with a kinase mix (Additional file 1: Table S8) and incubating at $37{ }^{\circ} \mathrm{C}$ for $60 \mathrm{~min}$, followed by incubation at room temperature for $10 \mathrm{~min}$. The samples were then incubated with a blunting mix (Additional file 1: Table S9) at $16{ }^{\circ} \mathrm{C}$ for $10 \mathrm{~min}$, followed by $12{ }^{\circ} \mathrm{C}$ for $20 \mathrm{~min}$, then incubation on ice for $30 \mathrm{~min}$. The samples were then purified using a MinElute PCR purification kit (Qiagen) following the manufacturer's instructions. 3' dA-tailing of the blunt DNA was performed by adding a dA-tailing mix (Additional file 1: Table S10) to each sample and incubating at $30{ }^{\circ} \mathrm{C}$ for $60 \mathrm{~min}$. The samples were then purified using a MinElute PCR purification kit (Qiagen) following the manufacturer's instructions. Oligonucleotide adapters and PCR primers are shown in Additional file 1: Table S11. The universal forward PCR primer was reconstituted to $25 \mu \mathrm{M}$ in TE buffer, and each of the reverse PCR primers was reconstituted to $10 \mu \mathrm{M}$ in TE buffer and frozen at $-80^{\circ} \mathrm{C}$ until use. Adapters $\mathrm{A}$ and $\mathrm{B}$ were combined and reconstituted in $5 \mathrm{X}$ CrimsonTaq Buffer (New England BioLabs) at a concentration of $5 \mu \mathrm{M}$ each and were frozen at $-80{ }^{\circ} \mathrm{C}$ until use. After thawing, the $\mathrm{A} / \mathrm{B}$ adapter mix was incubated on a PCR machine with the following settings: $25^{\circ} \mathrm{C}$ for $2 \mathrm{~min}, 95^{\circ} \mathrm{C}$ for $2 \mathrm{~min}, 72{ }^{\circ} \mathrm{C}$ for $1 \mathrm{~min}, 0.1{ }^{\circ} \mathrm{C} / \mathrm{s}$ to $30{ }^{\circ} \mathrm{C}, 30{ }^{\circ} \mathrm{C}$ for $5 \mathrm{~min}$, and $0.1{ }^{\circ} \mathrm{C} / \mathrm{s}$ to $4{ }^{\circ} \mathrm{C}$. The $\mathrm{A} / \mathrm{B}$ adapter mix was then diluted from 5 to $0.33 \mu \mathrm{M}$ by adding $1 \mathrm{X}$ T4 DNA Ligase Buffer (New England BioLabs) to the A/B adapter mix. The
$\mathrm{A} / \mathrm{B}$ adapter mix was then placed on ice, and $20 \mu \mathrm{L}$ of the $0.33 \mu \mathrm{M}$ A/B adapter mix was added to each DNA sample. A ligase mix was then added to each sample (Additional file 1: Table S12), and the samples were incubated at $22{ }^{\circ} \mathrm{C}$ for $4 \mathrm{~h}$. The samples were then purified using a MinElute PCR purification kit (Qiagen) following the manufacturer's instructions. Adapter-adapter ligation products were removed through RNACLEAN XP bead purification (Agencourt). The clear supernatant containing the RNACLEAN XP beads was used as PEG-wash Buffer. RNACLEAN XP beads were resuspended by vortexing, and $150 \mu \mathrm{L}$ was added to each sample. The samples were incubated at $22^{\circ}$ $\mathrm{C}$ on a thermomixer with maximum shaking for " $1 \mathrm{~min}$ on and $5 \mathrm{~min}$ off" for a total of $60 \mathrm{~min}$. The samples were placed on a magnetic stand (Millipore), and the supernatant was removed. The beads were washed with the PEG-wash buffer, and the samples were incubated on a thermomixer at $22{ }^{\circ} \mathrm{C}$ for 2 min with maximum shaking. The samples were placed back on the magnetic stand, and the supernatant was removed. The samples were washed three times with $80 \%$ ethanol while remaining on the magnetic stand, and the supernatant was discarded. The beads were then allowed to dry by room temperature incubation. DNA was eluted off the beads by adding TE buffer and alternating 2 min incubations at $42{ }^{\circ} \mathrm{C}$ and $5 \mathrm{~s}$ vortexes for a total of $8 \mathrm{~min}$. The samples were placed back on the magnetic stand, and the DNA containing supernatant was transferred to a new tube. The samples were then purified using a MinElute PCR purification kit (Qiagen) following the manufacturer's instructions. PCR reactions for multiplexed sequencing were then set up by adding a forward primer mix to each sample (Additional file 1: Table S13). The samples were incubated on ice for $5 \mathrm{~min}$. Phusion Hot Start Flex DNA Polymerase $1 \mu \mathrm{L}$ (New England BioLabs) and a designated reverse PCR primer $5 \mu \mathrm{L}$ were added to each sample. The samples were then incubated in a PCR machine with the following settings: $80^{\circ} \mathrm{C}$ for $2 \mathrm{~min}, 98{ }^{\circ} \mathrm{C}$ for $1 \mathrm{~min}, 2$ cycles $\left[98^{\circ} \mathrm{C}\right.$ for $30 \mathrm{~s}, 60^{\circ} \mathrm{C}$ for $30 \mathrm{~s}, 72^{\circ} \mathrm{C}$ for $30 \mathrm{~s}$, 13 cycles $\left[98{ }^{\circ} \mathrm{C}\right.$ for $30 \mathrm{~s}, 66{ }^{\circ} \mathrm{C}$ for $30 \mathrm{~s}, 72{ }^{\circ} \mathrm{C}$ for $30 \mathrm{~s}], 4$ cycles $\left[98^{\circ} \mathrm{C}\right.$ for $30 \mathrm{~s}, 66^{\circ} \mathrm{C}$ for $30 \mathrm{~s}, 72^{\circ} \mathrm{C}$ for $\left.60 \mathrm{~s}\right]$, and $72{ }^{\circ} \mathrm{C}$ for $7 \mathrm{~min}$ and then $4{ }^{\circ} \mathrm{C}$. The samples were then purified using a Qiaquick PCR purification kit (Qiagen) following the manufacturer's instructions. The samples were then pooled in equimolar concentrations and singleend ChIP-seq (50 nt) was performed on an Illumina HiSeq machine, resulting in 10-20 million reads/sample. The quality of samples was assessed using FastQC (http:// www.bioinformatics.babraham.ac.uk/projects/fastqc/) and ChIPQC [44]. All samples passed quality control measures, which are outlined in Additional file 1: Table S14.

\section{ChIP-seq mapping and data analysis}

This study makes use of data generated by the Blueprint Consortium. A full list of the investigators who contributed 
to the generation of the data is available from http:// www.blueprint-epigenome.eu. Funding for the project was provided by the European Union's Seventh Framework Programme (FP7/2007-2013) under grant agreement no. 282510-BLUEPRINT. The Blueprint dataset utilized was EGAD00001000913, which included ChIP-seq for H3K9me3 (2 $\mu \mathrm{g}$ antibody, Diagenode), H3K27me3 (1 $\mu \mathrm{g}$ antibody, Diagenode), H3K4me1 (2 $\mu \mathrm{g}$ antibody, Diagenode), H3K27ac (1 $\mu$ g antibody, Diagenode), and H3K36me3 (5 $\mu$ g antibody, Diagenode) on CD14-positive, CD16-negative classical monocytes from term neonatal umbilical cord blood and adult peripheral blood. For each of the histone modifications, three term neonatal samples and three adult samples were analyzed from the raw reads. Adapter sequences were trimmed from raw reads using Scythe (https://github.com/vsbuffalo/scythe), and the remaining reads were aligned to the Homo Sapiens genome assembly (Build 37, hg19) using Bowtie2 version 2.0.0 with default parameters [45]. Results were normalized to total read count. Peak calling was performed by comparing the ChIP samples to input samples with MACS2 [46]. Consensus peaksets were derived from the biological replicates using DiffBind and peaks needed to be present in two out of three replicates to be included in the consensus peaksets [47]. These consensus peaksets were then used for downstream analyses. Differentially bound sites were identified, and differential analysis was performed using the EdgeR package [48]. Sites were only considered to be differentially bound if the false discovery rate was $<0.1$. ChIPpeakAnno [49] was used to annotate enriched peaks and identify Gene Ontology terms associated with adjacent genes.

\section{Statistical analysis}

Prism 6 was used for basic data analysis. The differences between groups were evaluated with the student's $t$ test for parametric quantitative data, the Mann-Whitney test for nonparametric quantitative data, and ANOVA for multiple comparisons of parametric data. Values of $p<0.05$ were considered to be significant.

\section{Additional files}

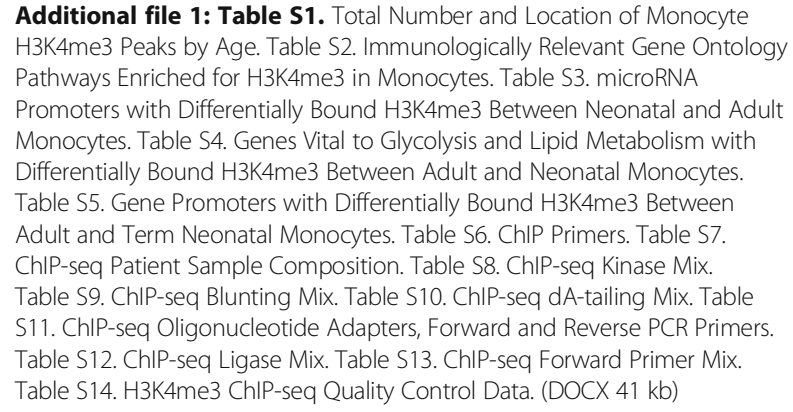

Additional file 1: Table S1. Total Number and Location of Monocyte H3K4me3 Peaks by Age. Table S2. Immunologically Relevant Gene Ontology Pathways Enriched for H3K4me3 in Monocytes. Table S3. microRNA Promoters with Differentially Bound H3K4me3 Between Neonatal and Adult Monocytes. Table S4. Genes Vital to Glycolysis and Lipid Metabolism with Differentially Bound H3K4me3 Between Adult and Neonatal Monocytes. Table S5. Gene Promoters with Differentially Bound H3K4me3 Between Adult and Term Neonatal Monocytes. Table S6. ChIP Primers. Table S7. ChIP-seq Patient Sample Composition. Table S8. ChIP-seq Kinase Mix. Table S9. ChIP-seq Blunting Mix. Table S10. ChIP-seq dA-tailing Mix. Table S11. ChIP-seq Oligonucleotide Adapters, Forward and Reverse PCR Primers. Table S12. ChIP-seq Ligase Mix. Table S13. ChIP-seq Forward Primer Mix. Table S14. H3K4me3 ChIP-seq Quality Control Data. (DOCX 41 kb)

Additional file 2: Figure S1. Gene ontology pathways associated with H3K4me3 peaks present only in adult monocytes. (A) Broad biological gene ontology pathways associated with $\mathrm{H} 3 \mathrm{~K} 4 \mathrm{me} 3$ monocyte peaks present in adult monocytes only. (B) Top 20 non-synonymous biological gene ontology pathways associated with adult monocyte H3K4me3 peaks. (PDF $36 \mathrm{~kb}$ )

Additional file 3: Figure S2. There are very few bivalent domains in neonatal and adult monocytes. (A) Venn diagram showing overlapping adult monocyte consensus peaks for $\mathrm{H} 3 \mathrm{~K} 4 \mathrm{me} 3, \mathrm{H} 3 \mathrm{~K} 9 \mathrm{me} 3$, and H3K27me3. (B) Venn diagram showing overlapping term neonatal monocyte consensus peaks for H3K4me3, H3K9me3, and H3K27me3. $\mathrm{H} 3 \mathrm{~K} 4 \mathrm{me} 3$ consensus peaks are obtained after only peaks present in at least two replicates are combined and analyzed. (PDF 680 kb)

Additional file 4: Figure S3. Adult monocytes demonstrate increased levels of the surface receptors CCR2 and CD300C by flow cytometry. (A) Representative density plot of CD14 + CCR2+ neonatal monocytes. (B) Representative density plot of CD14 + CCR2+ adult monocytes. (C) Representative density plot of CD14 + CD300C+ neonatal monocytes. (D) Representative density plot of CD14 + CD300C+ adult monocytes. (E) Representative density plot of CD14 + CXCR4+ neonatal monocytes. (F) Representative density plot of CD14 + CXCR4+ adult monocytes. (PDF $425 \mathrm{~kb}$ )

Additional file 5: Figure S4. Differential binding of $\mathrm{H} 3 \mathrm{~K} 4 \mathrm{me} 3$ at pro-inflammatory cytokine promoters during development results in differences in gene expression. (A) Increased binding of $\mathrm{H} 3 \mathrm{~K} 4 \mathrm{me} 3$ at the promoter site of $I L 1 B$ in adult monocytes is associated with increased ILIB mRNA and protein expression after LPS stimulation. (B) Increased binding of $\mathrm{H} 3 \mathrm{~K} 4 \mathrm{me} 3$ at the promoter site of TNF in adult monocytes is associated with increased TNF mRNA and protein expression after LPS stimulation. $A=$ adult, $T=$ term. H3K4me3 peaks display the read coverage for $\mathrm{H} 3 \mathrm{~K} 4 \mathrm{me} 3$ from one of the representative replicates from each group. Black bars display the H3K4me3 consensus peaks after only peaks present in at least two replicates are combined and analyzed. For the mRNA studies, adult $n=5$, term $n=5$. For the protein studies, adult $n=4$, term $n=4$. ${ }^{*} p<0.05,{ }^{* *} p<0.01$. (PDF $215 \mathrm{~kb}$ )

\section{Abbreviations}

Adult: Healthy adult; ChIP: Chromatin immunoprecipitation; ChIPseq: Chromatin immunoprecipitation followed by massively parallel sequencing; 030: 30-36 weeks gestation; Term: 37+ weeks gestation; TSSs: Transcriptional start sites; U30: Under 30 weeks gestation

\section{Acknowledgements}

We would like to thank Katherine Ravid, Nicholas Krepostman, Michael Lilly, Maria Faris, and Rachel Johnston for their assistance with sample processing and data acquisition.

\section{Funding}

This study was financially supported by the National Institutes of Health (T32HD751315 and K12HD028820-22), the Michigan Institute for Clinical and Health Research Pilot Grant (UL1TR000433), and the University of Michigan Amendt-Heller Newborn Research Award. None of these funding sources contributed to study design, data analysis or interpretation, or manuscript preparation.

\section{Availability of data and materials}

The dataset supporting the results are available in the GEO repository (GSE81957).

\section{Authors' contributions}

JRB, CMH, and MAS conceptualized the study. JRB, ADD, CMH, and MAS carried out the methodology of the study. JRB, ADD, and MAS participated in the formal analysis of the study. JRB and NJL investigated the study. ADD, $\mathrm{SLK}, \mathrm{NWL}$, and $\mathrm{CMH}$ contributed to the resources of the study. JRB wrote the original draft of the manuscript. JRB, NJL, ADD, SLK, NWL, CMH, and MAS wrote, reviewed, and edited the manuscript. JRB, SLK, NWL, CMH, and MAS carried out the funding acquisition of the study. SLK, NWL, CMH, and MAS supervised the study. All authors read and approved the final manuscript.

\section{Competing interests}

The authors declare that they have no competing interests. 


\section{Consent for publication}

Not applicable

\section{Ethics approval and consent to participate}

Enrollment of human subjects in this research project was approved by the University of Michigan Institutional Review Board (HUM00001441 and HUM00048716), and written informed consent was obtained from all participating adults and the parents of all participating neonates.

\section{Author details}

'Department of Pediatrics, Division of Neonatal-Perinatal Medicine, University of Michigan Medical Center, 1540 E. Medical Center Drive, C.S. Mott Children's Hospital Room 8-621, Ann Arbor, Ml 48109, USA. 'Department of Pathology, University of Michigan Medical Center, Ann Arbor, Ml 48109, USA. ${ }^{3}$ Department of Medicine, Division of Pulmonary \& Critical Care Medicine, Cedars-Sinai Medical Center, Los Angeles, CA 90048, USA

Received: 28 June 2016 Accepted: 8 September 2016 Published online: 20 September 2016

\section{References}

1. Sharma AA, Jen R, Butler A, Lavoie PM. The developing human preterm neonatal immune system: a case for more research in this area. Clin Immunol. 2012;145:61-8.

2. Stoll BJ, Hansen NI, Adams-Chapman I, Fanaroff AA, Hintz SR, Vohr B, et al. Neurodevelopmental and growth impairment among extremely lowbirth-weight infants with neonatal infection. JAMA. 2004;292:2357-65.

3. Levy O. Innate immunity of the newborn: basic mechanisms and clinical correlates. Nat Rev Immunol. 2007;7:379-90.

4. Adkins B. Neonatal immunology: responses to pathogenic microorganisms and epigenetics reveal an "immunodiverse" developmental state. Immunol Res. 2013;57:246-57.

5. Gordon S. Alternative activation of macrophages. Nat Rev Immunol. 2003;3:23-35.

6. Raghupathy R. Pregnancy: success and failure within the Th1/Th2/Th3 paradigm. Semin Immunol. 2001;13:219-27.

7. Smart JM, Kemp AS. Ontogeny of T-helper 1 and T-helper 2 cytokine production in childhood. Pediatr Allergy Immunol. 2001;12:181-7.

8. Strunk T, Temming P, Gembruch U, Reiss I, Bucsky P, Schultz C. Differential maturation of the innate immune response in human fetuses. Pediatr Res. 2004;56:219-26

9. Tatad AM, Nesin M, Peoples J, Cheung S, Lin H, Sison C, et al. Cytokine expression in response to bacterial antigens in preterm and term infant cord blood monocytes. Neonatology. 2008;94:8-15.

10. Philbin VJ, Dowling DJ, Gallington LC, Cortes G, Tan Z, Suter EE, et al. Imidazoquinoline Toll-like receptor 8 agonists activate human newborn monocytes and dendritic cells through adenosine-refractory and caspase-1dependent pathways. J Allergy Clin Immunol. 2012;130:195-204.e199.

11. Strunk T, Prosser A, Levy O, Philbin V, Simmer K, Doherty D, et al. Responsiveness of human monocytes to the commensal bacterium Staphylococcus epidermidis develops late in gestation. Pediatr Res. 2012;72:10-8.

12. Sharma AA, Jen R, Kan B, Sharma A, Marchant E, Tang A, et al. Impaired NLRP3 inflammasome activity during fetal development regulates IL-1 beta production in human monocytes. Eur J Immunol. 2015:45:238-49.

13. Barski A, Cuddapah S, Cui K, Roh TY, Schones DE, Wang Z, et al. High-resolution profiling of histone methylations in the human genome. Cell. 2007;129:823-37.

14. Saksouk N, Simboeck E, Dejardin J. Constitutive heterochromatin formation and transcription in mammals. Epigenetics Chromatin. 2015:8:3.

15. Creyghton MP, Cheng AW, Welstead GG, Kooistra T, Carey BW, Steine EJ, et al. Histone H3K27ac separates active from poised enhancers and predicts developmental state. Proc Natl Acad Sci U S A. 2010;107:21931-6.

16. Zentner GE, Tesar PJ, Scacheri PC. Epigenetic signatures distinguish multiple classes of enhancers with distinct cellular functions. Genome Res. 2011;21:1273-83.

17. Wagner EJ, Carpenter PB. Understanding the language of Lys36 methylation at histone H3. Nat Rev Mol Cell Biol. 2012;13:115-26.

18. Cui K, Zang C, Roh TY, Schones DE, Childs RW, Peng W, et al. Chromatin signatures in multipotent human hematopoietic stem cells indicate the fate of bivalent genes during differentiation. Cell Stem Cell. 2009;4:80-93.
19. Martino DJ, Tulic MK, Gordon L, Hodder M, Richman TR, Metcalfe J, et al. Evidence for age-related and individual-specific changes in DNA methylation profile of mononuclear cells during early immune development in humans. Epigenetics. 2011;6:1085-94.

20. Lederhuber H, Baer K, Altiok I, Sadeghi K, Herkner KR, Kasper DC. MicroRNA-146: tiny player in neonatal innate immunity? Neonatology. 2011;99:51-6.

21. Kent WJ, Sugnet CW, Furey TS, Roskin KM, Pringle TH, Zahler AM, et al. The human genome browser at UCSC. Genome Res. 2002;12:996-1006.

22. Tian $Y$, Jia Z, Wang J, Huang Z, Tang J, Zheng $Y$, et al. Global mapping of H3K4me1 and H3K4me3 reveals the chromatin state-based cell type-specific gene regulation in human Treg cells. PLoS One. 2011;6:e27770.

23. Sheedy FJ, Palsson-McDermott E, Hennessy EJ, Martin C, O'Leary JJ, Ruan Q, et al. Negative regulation of TLR4 via targeting of the proinflammatory tumor suppressor PDCD4 by the microRNA miR-21. Nat Immunol. 2010;11:141-7.

24. McGettrick AF, O'Neill LA. How metabolism generates signals during innate immunity and inflammation. J Biol Chem. 2013;288:22893-8.

25. Everts B, Amiel E, Huang SC, Smith AM, Chang CH, Lam WY, et al. TLRdriven early glycolytic reprogramming via the kinases TBK1-IKKvarepsilon supports the anabolic demands of dendritic cell activation. Nat Immunol. 2014:15:323-32.

26. Smith $C L$, Dickinson P, Forster T, Craigon M, Ross A, Khondoker MR, et al. Identification of a human neonatal immune-metabolic network associated with bacterial infection. Nat Commun. 2014;5:4649.

27. Ruthenburg AJ, Allis CD, Wysocka J. Methylation of lysine 4 on histone H3: intricacy of writing and reading a single epigenetic mark. Mol Cell. 2007;25:15-30.

28. Lauberth SM, Nakayama T, Wu X, Ferris AL, Tang Z, Hughes SH, et al. H3K4me3 interactions with TAF3 regulate preinitiation complex assembly and selective gene activation. Cell. 2013;152:1021-36.

29. Marchini G, Nelson A, Edner J, Lonne-Rahm S, Stavreus-Evers A, Hultenby K. Erythema toxicum neonatorum is an innate immune response to commensal microbes penetrated into the skin of the newborn infant. Pediatr Res. 2005;58:613-6.

30. Karlsson H, Hessle C, Rudin A. Innate immune responses of human neonatal cells to bacteria from the normal gastrointestinal flora. Infect Immun. 2002;70:6688-96.

31. Noval Rivas M, Burton OT, Wise P, Zhang YQ, Hobson SA, Garcia Lloret M, et al. A microbiota signature associated with experimental food allergy promotes allergic sensitization and anaphylaxis. J Allergy Clin Immunol. 2013;131:201-12.

32. Marra F, Marra CA, Richardson K, Lynd LD, Fitzgerald MJ. Antibiotic consumption in children prior to diagnosis of asthma. BMC Pulm Med. 2011;11:32.

33. Bhandare R, Schug J, Le Lay J, Fox A, Smirnova O, Liu C, et al. Genome-wide analysis of histone modifications in human pancreatic islets. Genome Res. 2010:20:428-33.

34. Cheng J, Blum R, Bowman C, Hu D, Shilatifard A, Shen S, et al. A role for $\mathrm{H} 3 \mathrm{~K} 4$ monomethylation in gene repression and partitioning of chromatin readers. Mol Cell. 2014:53:979-92.

35. Samson M, Jow MM, Wong CC, Fitzpatrick C, Aslanian A, Saucedo I, et al. The specification and global reprogramming of histone epigenetic marks during gamete formation and early embryo development in C. elegans. PLoS Genet. 2014;10:e1004588.

36. Kittan NA, Allen RM, Dhaliwal A, Cavassani KA, Schaller M, Gallagher KA, et al. Cytokine induced phenotypic and epigenetic signatures are key to establishing specific macrophage phenotypes. PLoS One. 2013;8:e78045.

37. Wen H, Dou Y, Hogaboam CM, Kunkel SL. Epigenetic regulation of dendritic cell-derived interleukin-12 facilitates immunosuppression after a severe innate immune response. Blood. 2008;111:1797-804.

38. Ishii M, Wen H, Corsa CA, Liu T, Coelho AL, Allen RM, et al. Epigenetic regulation of the alternatively activated macrophage phenotype. Blood. 2009:114:3244-54

39. Wei G, Wei L, Zhu J, Zang C, Hu-Li J, Yao Z, et al. Global mapping of $\mathrm{H} 3 \mathrm{~K} 4 \mathrm{me} 3$ and H3K27me3 reveals specificity and plasticity in lineage fate determination of differentiating CD4+ T cells. Immunity. 2009:30:155-67.

40. Leung A, Trac C, Du J, Natarajan R, Schones DE. Persistent chromatin modifications induced by high fat diet. J Biol Chem. 2016;291:10446-55.

41. Gallagher KA, Joshi A, Carson WF, Schaller M, Allen R, Mukerjee S, et al. Epigenetic changes in bone marrow progenitor cells influence the inflammatory phenotype and alter wound healing in type 2 diabetes. Diabetes. 2015:64:1420-30.

42. Wiegman CH, Li F, Clarke CJ, Jazrawi E, Kirkham P, Barnes PJ, et al. A comprehensive analysis of oxidative stress in the ozone-induced lung inflammation mouse model. Clin Sci (Lond). 2014;126:425-40. 
43. Raghuraman S, Donkin I, Versteyhe S, Barres R, Simar D. The emerging role of epigenetics in inflammation and immunometabolism. Trends Endocrinol Metab. 2016. doi: 10.1016/j.tem.2016.06.008.

44. Carroll TS, Liang Z, Salama R, Stark R, de Santiago I. Impact of artifact removal on ChIP quality metrics in ChIP-seq and ChIP-exo data. Front Genet. 2014;5:75.

45. Ourthiague DR, Birnbaum H, Ortenlof N, Vargas JD, Wollman R, Hoffmann A. Limited specificity of IRF3 and ISGF3 in the transcriptional innate-immune response to double-stranded RNA. J Leukoc Biol. 2015;98:119-28.

46. Liu L, Zinkgraf M, Petzold HE, Beers EP, Filkov V, Groover A. The Populus ARBORKNOX1 homeodomain transcription factor regulates woody growth through binding to evolutionarily conserved target genes of diverse function. New Phytol. 2015;205:682-94.

47. Ross-Innes CS, Stark R, Teschendorff AE, Holmes KA, Ali HR, Dunning MJ, et al. Differential oestrogen receptor binding is associated with clinical outcome in breast cancer. Nature. 2012;481:389-93.

48. Robinson MD, McCarthy DJ, Smyth GK. edgeR: a Bioconductor package for differential expression analysis of digital gene expression data. Bioinformatics. 2010;26:139-40.

49. Zhu L, Gazin C, Lawson ND, Pages H, Lin SM, Lapointe DS, et al. ChIPpeakAnno: a Bioconductor package to annotate ChIP-seq and ChIP-chip data. BMC Bioinformatics. 2010:11:237.

\section{Submit your next manuscript to BioMed Central} and we will help you at every step:

- We accept pre-submission inquiries

- Our selector tool helps you to find the most relevant journal

- We provide round the clock customer support

- Convenient online submission

- Thorough peer review

- Inclusion in PubMed and all major indexing services

- Maximum visibility for your research

Submit your manuscript at www.biomedcentral.com/submit 